\title{
GIANT LIPOSARCOMA IN SCAPULAR REGION: A CASE REPORT
}

Krishna Gopal ${ }^{1}$, Sanjeev Kumar², Sushmita ${ }^{3}$, Ashwani Kumar ${ }^{4}$, Ashish Prasad 5 , S. K. Jha ${ }^{6}$, K. H. Raghwendra7 , Sangeeta Pankaj ${ }^{8}$

\section{HOW TO CITE THIS ARTICLE:}

Krishna Gopal, Sanjeev Kumar, Sushmita, Ashwani Kumar, Ashish Prasad, S. K. Jha, K. H. Raghwendra, Sangeeta Pankaj. "Giant Liposarcoma in Scapular Region: A Case Report". Journal of Evolution of Medical and Dental Sciences 2014; Vol. 3, Issue 35, August 14; Page: 9264-9271, DOI: 10.14260/jemds/2014/3196

ABSTRACT: Liposarcoma is the most common soft tissue sarcoma in adults, which usually involves lower extremities, trunk, retroperitoneum, or abdominal cavity. Till date, only a few cases of enormously huge liposarcoma have been reported. We report a case of huge mass of size $60 \times 45 \times 35$ $\mathrm{cm}$ in scapular region in a middle aged person; which developed from a preexisting lipoma and was gradually increased in size as sub-mucosal non-ulcerated mass and which ultimately become ulcerated and infected with gas forming organisms. This tumor was successfully resected in toto under general anesthesia and after follow up for two years no recurrence was reported.

KEYWORDS: Huge liposarcoma, Scapular region ulceration, Surgical excision.

INTRODUCTION: Liposarcomas are the second most malignancy of soft tissue, which hallmark are lipoblasts or immature fat cell.1-3 These are usually found in late adult life and rarely in childhood with a male/female ratio of 2:1.1,4,5 Most of the cases are de novo and frequently develops from deep seated stroma rather than sub-mucosal or subcutaneous fat. 2,6

CASE REPORT: A 48 years male was presented to the outpatient department with chief complaint of backache due to a huge mass in upper back and foul smell. History revealed that a pea nut sized bulging was noticed by him in scapular region for 10 years and which had been increasing very slowly. When it attained the size of a cricket ball, he consulted a local surgeon, who advised him for fine needle aspiration cytology.

FNAC report primarily revealed to be an atypical lipomatous tumor; to which initially he ignored as it was not causing too much distress; but after 3 months he felt that this tumor had been increasing very rapidly; then he consulted us in our medical institute where on examination a foul smelling giant mass in the left scapular region was found (Fig-1); which was extending from mid axillary line to vertebral column and from shoulder to $12^{\text {th }}$ rib and on palpation it was non-tender and firm to hard in consistency. The skin over tumor was ulcerated on the lateral side.

The CT scan showed a $60 \times 45 \times 35 \mathrm{~cm}$ mass, occupying almost left half of back, extending to anterior chest wall up to midline, inferiorly up to left renal angle and crossing mid line posteriorly (Fig-2); which was non-enhancing, non-calcific, multi-compartmental soft tissue mass in relation to left scapula without obvious bony erosion; while X-ray of chest showed a huge smooth rounded opacity in the back of the chest wall without any bony involvement (Fig-3). His ultrasound report of pelvic and abdominal regions was normal. Trucut biopsy reported the mass primarily to be a low grade liposarcoma.

After thorough clinical examination; wide surgical excision of this tumor was planned under general anesthesia and hence the patient was sent for pre anesthetic evaluation where he was investigated properly. Except being thin built and low hemoglobin ( $\mathrm{Hb}-9.5 \mathrm{gm} \%$ ) his routine 
hematological, biochemical and serological investigations were within normal limits. Hence one unit of blood was transfused after cross matching and blood bank was informed to keep ready sufficient amount of blood.

Since the tumor was so huge that laying in supine position to this patient was not possible; hence under all vitals monitoring like ECG, $\mathrm{SPO}_{2}, \mathrm{ETCO}_{2}$, NIBP, CVP and temperature he was intubated for general anesthesia with a flexo-metallic endo-tracheal tube of $8 \mathrm{~mm}$ internal diameter in lateral position by our anesthesia team.

An elliptical incision was made and skin flaps were raised, and the tumor was resected in toto with preservation of the muscles, vessels \& nerves and hemostasis was secured and wound was closed (Fig-4). Intraoperative period was uneventful except two unit of blood was transfused due to some blood loss. The total excised specimen of tumor was weighted $16 \mathrm{Kgs}$ and was sent for histopathology. During post-operative the patient was stable.

Stitches were removed on $14^{\text {th }}$ post-operative day (Fig-5). Final histopathological report revealed that the tumor had sheets of adipocytes in a uniform pattern and lipoblasts present in it which have large atypical nuclei suggestive of an adipocytic liposarcoma (Fig-6). The Patient was referred to the department of oncology for further management, where he was advised for follow up.

The patient came for first follow up after three months; found a healthy scar without any signs of local recurrence. The patient had been visiting regularly in our OPD for follow up and in last visit after passing two years of surgery; no any sign of recurrence was found.

DISCUSSION: The original description of the "lipoma-like" liposarcoma was first of all given by Enterline et al.7,8 Liposarcomas are the most common soft tissue sarcoma; which accounts approximately $16-18 \%$ of all mesenchymal malignancies ${ }^{3,9}$ and usually involve trunk especially retroperitoneum or abdominal cavity (42\%), lower extremities (41\%); apart from these they may occur at upper extremity (11\%), head and neck region include the larynx, hypopharynx, oral cavity, orbit, scalp and soft tissues of the neck (6\%) and more rarely in mediastinum \& scrotum/spermatic cord. ${ }^{1-3,6,10-16}$

Considering currently available data liposarcomas are divided into several subtypes as welldifferentiated, myxoid, round cell, pleomorphic, and dedifferentiated; but broadly they may be conceptualized in to two groups myxoid/round cell and well differentiated/dedifferentiated liposarcomas ${ }^{1,2}$. Most of myxoid/round cell liposarcomas of are found primarily in the limb and their severity may vary from low grade to high-grade tumor as seen in pure myxoid and pure round cell liposarcoma respectively; but in some cases transitional features may also be seen which behavior may depend upon the presence of round cell quantity. ${ }^{2,6}$

The well-differentiated/dedifferentiated liposarcomas occur in elderly age as limb or retroperitoneal lesions; which contain mature fat mingle with atypical hyperchromatic cells and seldom lipoblasts; which are characterized by a worsen prognosis because of their higher recurrence rate, ${ }^{17}$ and usually these tumor do not metastasize, ${ }^{2}$ although their behavior depends on their histological grading and also strongly influenced by location as worse prognosis is seen in retroperitoneal liposarcomas, $2,18,19$ but the role of the size of tumor in prognosis is not clear. ${ }^{12}$

In 2002; WHO has classified well-differentiated liposarcoma into four subtypes as adipocytic (or lipoma-like), sclerosing, inflammatory, and spindle cell liposarcomas; in which commonest is adipocytic or lipoma-like liposarcoma where proliferation of relatively mature adipocytes found ${ }^{11}$. 
Sclerosing liposarcoma is the next common type and most frequently found as retroperitoneal or paratesticular lesions; and characterized by the presence of bizarre stromal cells with marked nuclear hyperchromasia and rarely multivacuolated lipoblasts mixed in fibrillary collagenous stroma; and occasionally these fibrous component may represent the most of the neoplasm. Inflammatory variety is rarely seen; which occurs most often in the retroperitoneal area; where chronic inflammatory cells are predominantly infiltrated in relatively mature adipocytes. ${ }^{16}$

The spindle-cell liposarcoma is quite common which usually occur in subcutaneous tissue of the upper extremities and shoulder region; where relatively bland neural appearing spindle cells mixed with fibrous and/or myxoid stroma of atypical liposarcomatous component are found 21 .

The myxoid subtype accounts for $50 \%$ of all liposarcomas ${ }^{22}$; and they have predilection for the limbs.

Albeit rare, such tumors arise in the sub-cutis with involvement of dermis and are seen most often in male patients and in an acral location; and histologically they contain mature adipocytes, thick-walled blood vessels, and smooth muscle cells arranged in well-defined fascicles and around blood vessels, ${ }^{23}$ while in pleomorphic liposarcoma CT or MR imaging shows an intense enhancement, adjacent organs invasion, vascular infiltration, calcification or ossification, and areas of necrosis or hemorrhage. 24,25

Recently karyotypic analysis in about $80 \%$ of well-differentiated liposarcomas has shown that this group of mesenchymal neoplasm is characterized by the presence of supernumerary rings or giant marker chromosomes, or both; which contain amplified sequences derived from the chromosomal region 12q13-15; wherein they map several proto-oncogenes such as MDM2, CDK4, HMGA2, SAS, GLI, DDTI3, OS1, and OS9; which play important roles in the molecular pathogenesis of human neoplasia. According to another authors the immunostaining of CDK4 and MDM2 proteins have been recognized as an important adjunct for differentiating the benign lipoma from welldifferentiated liposarcoma. ${ }^{11,26-33}$

CT scan of liposarcoma usually shows well-circumscribed lobulated mass with multiple septations and variable contrast enhancement and on caparison with MRI found that CT scan is superior for evaluating of cortical bone erosion and tumor mineralization. MRI findings of different types liposarcomas can be correlated with the histo-pathologic features and found that all such tumors showed well-defined margins; in which the well-differentiated liposarcomas were composed mainly of fat with septations or nodules, were hyper-intense on $\mathrm{T}_{2}$-weighted images, and demonstrated faint enhancement or no enhancement following intravenous contrast; while myxoid liposarcomas were homogeneous or mildly heterogeneous; although in some cases pseudo-capsules were also seen. ${ }^{4,20}$

Pleomorphic type of liposarcomas showed a markedly heterogeneous internal structure. Both myxoid and pleomorphic liposarcomas showed moderate or marked heterogeneous enhancement after contrast administration. Well-differentiated liposarcomas may be differentiated from other types of the tumor by their largely lipomatous appearance. The malignancy grade increases in parallel with tumor heterogeneity and contrast enhancement. 20,34

The role of radiation in liposarcomas is debatable, sometimes it may be beneficial adjunct to surgery in cases where wide marginal resection of tumor was possible. According to some authors the risk of local recurrence may reduce with radiation therapy, ${ }^{34-36}$ but others are claimed that this may aggravate dedifferentiation to a higher grade in case of recurrence. Nevertheless patient with 
large high grade liposarcomas may be benefited by use of multimodality treatment along with chemoradiation; but still use of chemotherapy in liposarcomas is experimental. ${ }^{37}$

In conclusion, giant liposarcomas in scapular region are extremely rare; and possible differential diagnosis may be lipoma, lipoblastoma, pleomorphic lipoma, chondroid lipoma, hibernoma and neurofibroma etc. ${ }^{22,36}$ Their choice of treatment is wide surgical excision; although with incomplete excision chances of recurrence is $17 \%$ to $80 \% 37$ and overall mortality varies from $0 \%$ for surgical resectable soft tissue to $80 \%$ for high grade retroperitoneal liposarcomas. ${ }^{11}$ We stress the importance of meticulous evaluation of all required investigations like biopsy, CT or MRI to see extent of lesion, prior to successful surgical and other management.

\section{REFERENCES:}

1. Barile A, Zugaro L, Catalucci A, Caulo M, Di Cesare E, Splendiani A, Gallucci M, Masciocchi C. Soft tissue liposarcoma: histological subtypes, MRI and CT findings. Radiol Med. 2002 Sep; 104 (3):140-9.

2. Weiss SW. Lipomatous tumors. Monogr Pathol. 1996; 38: 207-239.

3. Munk PC, Lee M J, Janzen D L, Connell D G, Logan P M, Poon P Y, Bainbridge T C. Lipoma \& Liposarcoma: Evaluation using C T and MR Imaging. Aajr 1997;169: 589-594.

4. Meloni F, Feo C F, Profili S, Cossu M L, Meloni G B. Omental well-differentiated liposarcoma: US, CT and MR findings. Int J Biomed Sci 2009; 5 (3): 302-304.

5. Milic DJ, Rajkovic MM, Zivic SS. Primary liposarcomas of the omentum: a report of two cases. Eur J Gastroenterol Hepatol 2004; 16: 5.

6. Henricks W H, Chu Y C, Goldblum J R, Weiss S W. Dedifferentiated liposarcoma: a clinicopathological analysis of 155 cases with a proposal for an expanded definition of dedifferentiation. Am J Surg Pathol 1997 Mar;21 (3): 271-81.

7. Enterline HT, Culberson JD, Rochlin DB, Brady IW. Liposarcoma: A clinical and pathological study of 53 cases. Cancer 13:932-950, 1960.

8. Evans HL, Sonle EH, Winkelmann RK. Atypical lipoma, atypical intramuscular and well differentiated retroperitoneal liposarcoma: A reappraisal of 30 cases formerly classified as well differentiated liposarcoma. Cancer 43: 574-584, 1979

9. Arkun R, Memis A, Akalin T, Ustun EE, Sabah D, Kandiloglu G. Liposarcoma of soft tissue: MRI findings with pathologic correlation. Skeletal Radiol. 1997 Mar; 26 (3): 167-7.

10. Goldblum JR, Weiss SW; Enzinger and Weiss's Soft tissue tumors; 4th Mosby Pub.; 2001. Liposarcoma: Goldblum JR and Weiss SD (edi) pp. 662-71 Andrew L.F, Carrie Y; Welldifferentiated Liposarcoma/Atypical Lipomatous Tumors,

11. Bone and Soft Tissue Pathology: A Volume in the Series Foundations in Diagnostic Pathology.

12. V. Pruna, Narcisa Bucur, Angela Neacsu, A. Giovani, Anca Buliman, M. Gorgan. Giant extracranial liposarcoma - Case report. Romanian Neurosurgery (2010) XVII 2: 214 - 218

13. Golledge J, Fisher C, Rhys-Evans PH. Head and neck liposarcoma. Cancer 76:1051-1058, 1995.

14. McNab AA, Moseley I. Primary orbital liposarcoma: clinical and computed tomographic features. British Journal of Ophthalmology, 1990, 74, 437-439

15. McCulloch TM, Makielski KH, McNutt MA. Head and neck liposarcoma. A histopathologic reevaluation of reported cases. Arch Otolaryngol Head Neck Surg 118: 1045-1049, 1992. 
16. Sunwoo MO, Park HY, Oh HK, Choi HY. Dedifferentiated Liposarcoma of the thigh: Case report. J Korean Radiol Soc.2002; 47 (5): 527-31.

17. Singer S, Antonescu CR, Riedel E, Brennan MF. Histologic subtype and margin of resection predict pattern of recurrence and survival for retroperitoneal liposarcoma. Ann Surg. 2003; 238: 358-370

18. Fletcher C, Unni K, Mertens F. Pathology and Genetics of Tumors of Soft Tissue and Bone. Lyon, France: International Agency for Research on Cancer Press; 2002.

19. Dalal KM, Antonescu CR, Singer S. Diagnosis and management of lipomatous tumors. J Surg Oncol. 2008; 97 (4): 298-313.

20. Mavrogenis AF, Papagelopoulos PJ. Well-differentiated liposarcoma. Atlas Genet Cytogenet Oncol Haematol. 2013; 17 (8): 579-582.

21. Mentzel T, Fletcher CD. Lipomatous tumours of soft tissues: an update. Virchows Arch. 1995; 427 (4): 353-63.

22. Pereira JM, Sirlin CB, Pinto PS, Casola G. CT and MR imaging of extrahepatic fatty masses of the abdomen and pelvis: techniques, diagnosis, differential diagnosis, and pitfalls. Radiographics. 2005; 25: 69-85.

23. Mentzel T. Cutaneous lipomatous neoplasms. Semin Diagn Pathol. 2001 Nov; 18 (4): 250-7.

24. Tateishi U, Hasegawa T, Beppu Y, Satake M, et al. Primary dedifferentiated liposarcoma of the retroperitoneum. Prognostic significance of computed tomography and magnetic resonance imaging features. J Comput Assist Tomogr. 2003; 27: 799-804.

25. Unal B, Bilgili YK, Batislam E, Erdogan S. Giant dedifferentiated retroperitoneal liposarcoma: CT and MRI findings. Eur J Radiol Extra. 2004; 51: 47-50.

26. Distinct mdm2/p53 expression patterns in liposarcoma subgroups: implications for different pathogenetic mechanisms. J Pathol. 1997; 181 (1): 14-24.

27. Shimada S, Ishizawa T, Ishizawa K, Matsumura T, Hasegawa T, Hirose T. The value of MDM 2 and CDK4 amplification levels using real-time polymerase chain reaction for the differential diagnosis of liposarcomas and their histologic mimickers. Hum Pathol. 2006; 37 (9): 11231129.

28. Binh MB, Sastre-Garau X, Guillou L, et al. MDM2 and CDK4 immunostainings are useful adjuncts in diagnosing well-differentiated and dedifferentiated liposarcoma subtypes: a comparative analysis of 559 soft tissue neoplasms with genetic data. Am J Surg Pathol. 2005; 29 (10): 13401347

29. Weaver J, Downs-Kelly E, Goldblum JR, et al. Fluorescence in situ hybridization for MDM2 gene amplification as a diagnostic tool in lipomatous neoplasms. Mod Pathol. 2008; 21 (8): 943-949.

30. Weaver J, Rao P, Goldblum JR, et al. Can MDM2 analytical tests performed on core needle biopsy be relied upon to diagnose well-differentiated liposarcoma. Mod Pathol. 2010; 23 (10): 13011306.

31. Hostein I, Pelmus M, Aurias A, Pedeutour F, Mathoulin-Pélissier S, Coindre JM. Evaluation of MDM2 and CDK4 amplification by real-time PCR on paraffin wax embedded material: a potential tool for the diagnosis of atypical lipomatous tumours/ well-differentiated liposarcomas. J Pathol. 2004; 202 (1): 95-102. 
32. Italiano A, Bianchini L, Keslair F, et al. HMGA2 is the partner of MDM2 in well differentiated and dedifferentiated liposarcomas whereas CDK4 belongs to a distinct inconsistent amplicon. Int J Cancer. 2008; 122 (10): 2233-2241.

33. Italiano A, Bianchini L, Gjernes E, et al. Clinical and biological significance of CDK4 amplification in well-differentiated and dedifferentiated liposarcomas. Clin Cancer Res. 2009; 15 (18): 56965703.

34. Andreas F. Mavrogenis; Jan Lesensky; Carlo R; Alberghini M, Letson G, Ruggieri P. Atypical lipomatous tumors/welldifferentiated Liposarcomas: clinical outcome of 67 patients. Orthopedics; December 2011 | Volume 34; Number 12; e893- e898.

35. Zagars GK, Goswitz MS, Pollack A. Liposarcoma: outcome and prognostic factors following conservation surgery and radiation therapy. Int J Radiat Oncol Biol Phys. 1996; 36 (2): 311-319.

36. Sommerville SM, Patton JT, Luscombe JC, Mangham DC, Grimer RJ. Clinical outcomes of deep atypical lipomas (well-differentiated lipoma-like liposarcomas) of the extremities. ANZ J Surg. 2005; 75(9): 803-806.

37. Pack GT, Pierson JC. Liposarcoma; a study of 105 cases. Surgery 36:687-712, 1954.

Fig. 1: Giant mass in the left scapular region.

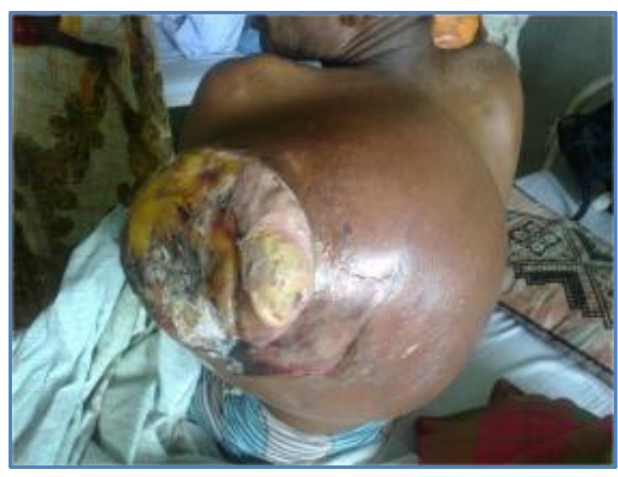

Fig. 1

Fig. 2: The CT scan showing a well-circumscribed lobulated mass of size $60 \times 45 \times 35 \mathrm{~cm}$, with multiple septations and variable contrast enhancement extending to anterior chest wall up to midline, inferiorly up to left renal angle and crossing mid line posteriorly.

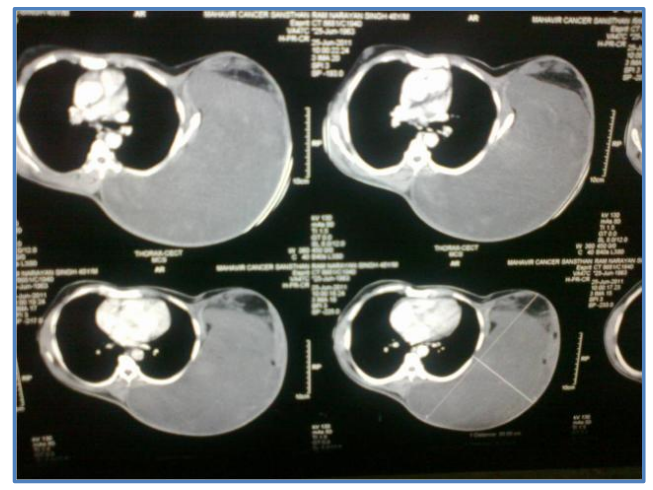

Fig. 2 


\section{CASE REPORT}

Fig. 3: X-ray of chest showing a huge smooth rounded opacity in the back of the chest wall without any bony involvement.

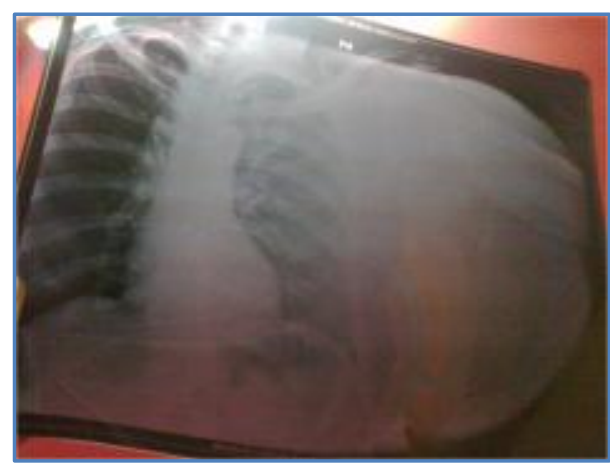

\section{Fig. 3}

Fig. 4: Intraoperative picture.

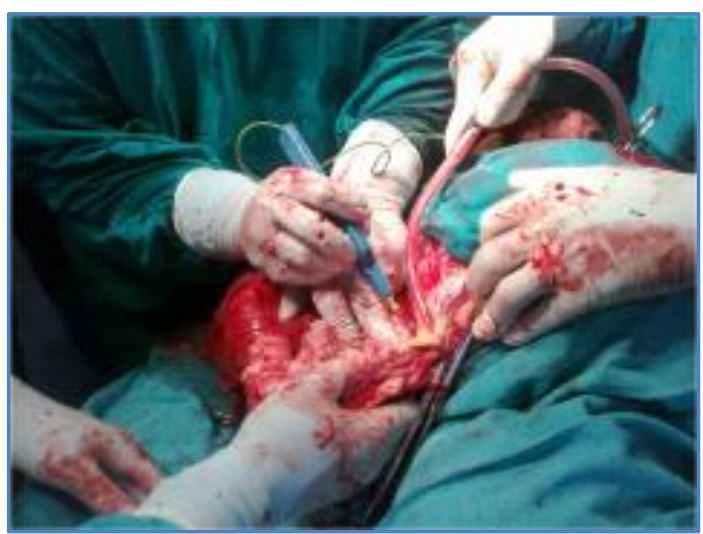

Fig. 4

Fig. 5: Post-operative patient just after removal of stitches.

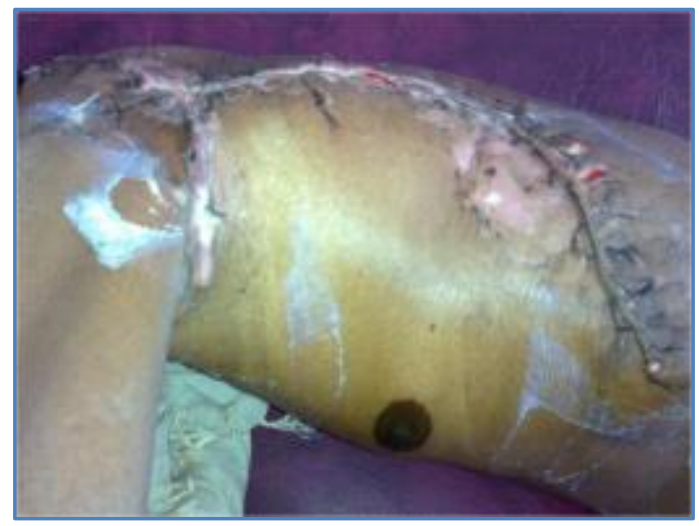

\section{Fig. 5}


Fig. 6: Light microscopy of excised tumor showing sheets of adipocytes in a uniform pattern and lipoblasts present in it which have large atypical nuclei. (H\& E stain, X 100).

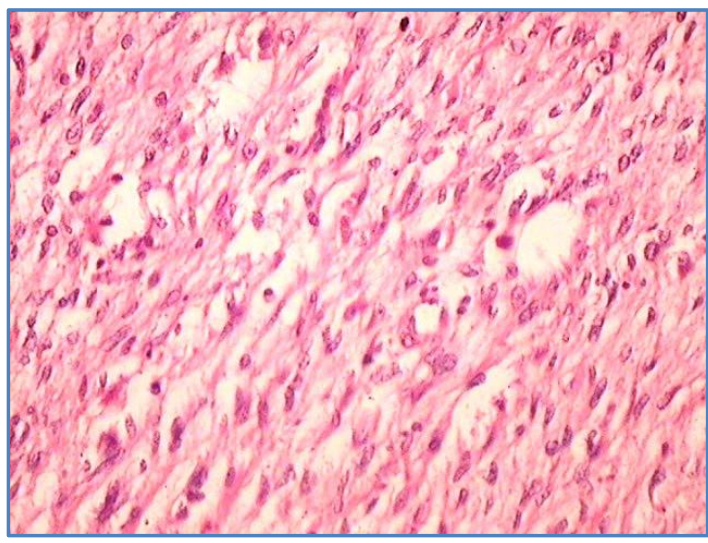

\section{Fig. 6}

\section{AUTHORS:}

1. Krishna Gopal

2. Sanjeev Kumar

3. Sushmita

4. Ashwani Kumar

5. Ashish Prasad

6. S. K. Jha

7. K. H. Raghwendra

8. Sangeeta Pankaj

\section{PARTICULARS OF CONTRIBUTORS:}

1. Assistant Professor, Department of General Surgery, IGIMS, Patna.

2. Additional Professor, Department of Anaesthesiology \& Critical Care Medicine, IGIMS, Patna.

3. Lecturer, Department of Maxillofacial \& Dental Surgery, BRAIDS, Patna.

4. Senior Resident, Department of General Surgery, IGIMS, Patna.

5. Senior Resident, Department of General Surgery, IGIMS, Patna.

6. Professor, Department of General Surgery, IGIMS, Patna.
7. Professor, Department of Anaesthesiology \& Critical Care Medicine, IGIMS, Patna.

8. Associate Professor, Department of Gynaecology Oncology, RCC, IGIMS, Patna.

\section{NAME ADDRESS EMAIL ID OF THE CORRESPONDING AUTHOR:}

Dr. Krishna Gopal,

Assistant Professor,

Department of General Surgery,

Indira Gandhi Institute of Medical Sciences,

Patna-800014, Bihar, India.

Email: gopakrishh@gmail.com

Date of Submission: 28/07/2014.

Date of Peer Review: 29/07/2014.

Date of Acceptance: 06/08/2014.

Date of Publishing: 13/08/2014. 